\title{
CONSUMO E DIGESTIBILIDADE APARENTE DAS SILAGENS DE SEIS GENÓTIPOS DE MILHO PRECOCE OU SUPER-PRECOCE ${ }^{1}$
}

\author{
Rafael Dantas dos Santos ${ }^{2}$, Luiz Gustavo Ribeiro Pereira ${ }^{3}$, Gherman Garcia Leal de Araújo ${ }^{3}$, Tadeu \\ Vinhas Voltolini ${ }^{3}$, Salete Alves de Moraes ${ }^{3}$, André Luis Alves Neves ${ }^{4}$, Cleber Tiago Ferreira Costa ${ }^{5}$ \\ ${ }^{1}$ Parte da Dissertação de Mestrado do primeiro autor; \\ ${ }^{2}$ Analista da Embrapa Semi-Árido / Aluno do curso de Mestrado em Ciência Animal da Universidade Federal do Vale do São \\ Francisco - UNIVASF. E-mail: rafael.dantas@cpatsa.embrapa.br; \\ ${ }^{3}$ Pesquisadores da Embrapa Semi-Árido; \\ ${ }^{4}$ Analista Embrapa Gado de Leite; \\ ${ }^{5}$ Aluno do curso de Mestrado em Ciência Animal - UNIVASF.
}

Resumo: Avaliaram-se o consumo médio diário e a digestibilidade aparente da matéria seca (MS), matéria orgânica (MO) e proteína bruta (PB) das silagens de seis genótipos de milho de ciclo precoce e superprecoce (BRS Caatingueiro, BRS Assum Preto, BR 5033 - Asa Branca, BR 5028 - São Francisco, Gurutuba e BRS 4103) recomendados para a região nordeste. Foram utilizados 24 carneiros, machos, castrados, alojados em gaiolas metabólicas. O delineamento experimental utilizado foi o inteiramente casualizado com seis tratamentos e quatro repetições, as médias foram comparadas pelo teste de Tukey. Não foram observadas diferenças entre os genótipos quanto ao consumo e digestibilidade aparente da MS, MO e da PB (P>0,05). Os consumos médios de MS, MO e PB foram de 676 , 646 e 41,5 g/dia, respectivamente. Os valores médios de digestibilidade da MS, MO e PB foram, respectivamente, de 64,0, 64,8 , e $53,1 \%$, resultados compatíveis com o das silagens de genótipos comumente indicados e utilizados para a produção de silagens. Genótipos de ciclo precoce e super-precoce, constituem-se como opção volumosa suplementar na forma de silagem em condições Semi-Áridas.

Palavras-chave: consumo, digestibilidade, milho, ruminantes, silagem

\section{INTAKE AND DIGESTIBILITY OF SILAGES OF SIX MAIZE EARLY OR SUPER EARLY GENOTYPES}

\begin{abstract}
The daily average intake and the apparent digestibility of dry matter (DM), organic matter (OM) and crude protein (CP) of the silages of six maize early and super early genotypes (BRS Caatingueiro, BRS Assum Preto, BR 5033 - Asa Branca, BR 5028 - São Francisco, Gurutuba and BRS 4103) recommended for the northeast region were evaluated. Twenty four sheep, male, castrated aind housed in metabolic cageswere used. The experiment design was completely randomized with six treatments and four replicas, the averages was compared by Tukey test. There were no differences between genotypes for intake and apparent digestibility of DM, OM and CP (P>0.05). The average intake of DM, OM, CP were 675.6, 646 and $41.5 \mathrm{~g} /$ day, respectively. The average values of digestibility of DM, $\mathrm{OM}, \mathrm{CP}$ were $64.0,64.8$, and $53.1 \%$ respectively, consistent with the results of commonly used corn genotypes for silage. Early and super-early corn genotypes are options for silage production in Semi-Arid conditions.
\end{abstract}

Keywords: intake, digestibility, corn, ruminants, silage

\section{Introdução}

A cultura do milho assume papel de destaque na economia do Nordeste do Brasil por participar representativamente na geração da renda agrícola e pelo papel importante na alimentação humana e animal. No entanto, os sistemas de produção da região semi-árida brasileira são caracterizados pela baixa produtividade do milho, provocada principalmente, pela instabilidade pluvial, altas temperaturas e o baixo nível tecnológico adotado pelos produtores (Carvalho 2007).

Na região semi-árida nordestina, as chances de sucesso e produção máxima no cultivo do milho são de aproximadamente $10 \%$, o que revela as frequentes perdas e baixa produtividade da lavoura. Assim, a utilização de materiais genéticos precoces e super precoces podem ser uma alternativa para evitar, ou minimizar, as conseqüências geradas por esta particularidade climática regional.

Alguns genótipos com estas características encontram-se disponíveis no mercado, entretanto ainda não foram avaliados na forma de silagem. Estes estudos são importantes e podem ser o ponto inicial para o melhoramento do milho para produção de silagem em condições semi-áridas. Reforçando a importância 
deste tipo de pesquisa, pesquisadores têm enfatizado que o desenvolvimento de cultivares modernos, mais eficientes e adaptados às condições locais permitem ganhos efetivos em produtividade e qualidade nutricional.

Este trabalho foi conduzido com o objetivo de determinar o consumo e a digestibilidade aparente da matéria seca, matéria orgânica e proteína bruta das silagens de seis genótipos de milho de ciclo precoce ou super-precoce.

\section{Material e Métodos}

Utilizaram-se seis genótipos de milho, sendo três de ciclo precoce, BR 5033 - Asa Branca, BR 5028 - São Francisco e BRS 4103 e três de ciclo super precoce, BRS Assum Preto, Gurutuba e BRS Caatingueiro. Os genótipos foram produzidos nas dependências da Embrapa Semi-Árido, localizado no município de Petrolina-PE.

As plantas foram colhidas quando apresentavam grãos no estádio farináceo-duro, sendo cortadas rente ao solo, amontoadas e picadas em ensiladeira estacionária, ajustada para produção de partículas de aproximadamente $2 \mathrm{~cm}$. O material foi imediatamente ensilado em 18 manilhas de concreto (capacidade para 250 litros), revestidas internamente com lona plástica. O conteúdo de cada manilha foi compactado por pisoteio e a vedação foi feita com lona plástica e fitas adesivas.

Foram utilizados 24 carneiros adultos, castrados, sem raça definida e com peso vivo médio de 19 Kg. Os animais foram adaptados à alimentação, às gaiolas metabólicas e às bolsas coletoras durante um período de 17 dias (período pré-experimental). O período de coleta (período experimental) foi de cinco dias. Os animais foram pesados no início e no final dos períodos.

A quantidade de silagem fornecida, as sobras e a produção total de fezes e urina foram avaliadas diariamente. Amostras desses materiais foram acondicionadas em sacos plásticos, identificadas e congeladas para análises posteriores. $\mathrm{O}$ arraçoamento ocorreu de forma a se obterem $15 \%$ de sobras, que eram coletadas e pesadas antes de cada novo fornecimento.

As análises bromatológicas (MS, MO e PB) dos alimentos, das sobras e das fezes foram determinadas conforme Silva e Queiroz (2002). Os valores de digestibilidade aparente dos nutrientes foram obtidos conforme metodologia proposta por Silva e Leão (1979) Utilizou-se o delineamento inteiramente ao acaso, com seis tratamentos e quatro repetições. Os dados obtidos foram submetidos à análise de variância utilizando-se o programa estatístico ASSISTAT versão 7.5 beta (2008) e as médias comparadas pelo teste de Tukey ao nível de 5\% de probabilidade.

\section{Resultados e Discussão}

Os teores médios de matéria seca (MS), matéria orgânica (MO), proteína bruta (PB), fibra em detergente neutro (FDN), fibra em detergente ácido (FDA) e digestibilidade in vitro da matéria seca (DIVMS) das silagens dos genótipos avaliados podem ser observados na tabela 1.

Tabela 1. Teores médios de MS, MO, PB, FDA, FDN e DIVMS das diferentes silagens

\begin{tabular}{lcccccc}
\hline Genótipos & MS (\%) & MO* & PB* & FDN & FDA & DIVMS \\
\hline Caatingueiro & 29,92 & 94,65 & 6,42 & 48,12 & 24,05 & 62,51 \\
Assum Preto & 25,60 & 94,55 & 6,42 & 48,15 & 23,61 & 65,77 \\
Asa Branca & 23,42 & 95,10 & 6,15 & 51,34 & 26,09 & 62,12 \\
São Francisco & 28,14 & 95,36 & 5,57 & 51,70 & 26,56 & 59,91 \\
Gurutuba & 26,26 & 94,38 & 6,99 & 45,91 & 23,49 & 65,34 \\
BRS 4103 & 26,24 & 95,63 & 6,21 & 45,25 & 23,36 & 61,90 \\
\hline * Dados em porcentagem da matéria seca. & & & & &
\end{tabular}

Apesar destes genótipos, geralmente, não serem utilizados para produção de silagem os valores são compatíveis com os dados médios citados por Valadares Filho (2006) na Tabela Brasileira de Composição de Alimentos, onde foram reportados os valores de 30,92\% de MS, 94,74\% de MO, 7,26\% de PB, 55,41\% de FDN, 30,67\% de FDA e 62,26\% de DIVMS.

Na tabela 2 estão apresentados o consumo médio diário (CM) e a digestibilidade aparente (DA) das silagens dos seis genótipos de milho. 
Tabela 2. Consumo (g/dia e g/ $\mathrm{kg}^{0,75}$ ) e digestibilidade aparente da matéria seca (MS), matéria orgânica (MO) e proteína bruta $(\mathrm{PB})$ das silagens de seis genótipos de milho

\begin{tabular}{lccccccccc}
\hline & \multicolumn{3}{c}{ Consumo g/dia } & \multicolumn{3}{c}{ Consumo g/kg ${ }^{0,75}$} & \multicolumn{3}{c}{ Digestibilidade Aparente \% } \\
\hline Genótipos & MS & MO & PB & MS & MO & PB & MS & MO & PB \\
\hline Caatingueiro & 735 & 704 & 43,7 & 77,7 & 74,4 & 4,6 & 65,6 & 67,4 & 54,4 \\
Assum Preto & 701 & 663 & 45,8 & 72,3 & 68,4 & 4,7 & 64,0 & 65,2 & 55,3 \\
Asa Branca & 638 & 609 & 38,5 & 66,7 & 63,6 & 4,0 & 62,3 & 64,1 & 51,5 \\
São Francisco & 698 & 689 & 39,0 & 67,4 & 66,3 & 3,8 & 65,6 & 67,5 & 51,3 \\
Gurutuba & 579 & 547 & 40,2 & 61,3 & 58,0 & 4,3 & 65,1 & 66,9 & 57,7 \\
BRS 4103 & 703 & 664 & 42,2 & 69,2 & 66,6 & 4,2 & 61,7 & 58,0 & 48,7 \\
\hline \multicolumn{1}{r}{ CV } & 17,1 & 17,6 & 17,1 & 12,2 & 12,0 & 11,9 & 8,8 & 7,3 & 19,0 \\
\hline
\end{tabular}

Médias seguidas com letras semelhantes, na mesma linha, não diferem estatisticamente $(\mathrm{P}<0,05)$ pelo teste de Tukey

Não foram observadas diferenças entre os tratamentos $(\mathrm{P}>0,05)$ para o consumo da matéria seca, matéria orgânica e proteína bruta. $\mathrm{O}$ mesmo ocorreu para os coeficientes de digestibilidade $(\mathrm{P}>0,05)$.

Os resultados encontrados para consumo e digestibilidade da PB foram semelhantes aos obtidos por Freitas et al. (2003) que trabalharam com os genótipos HT01, HT47C, HT129, AG5011 e BR3123 e relataram consumo médio de $4,6 \mathrm{~g} / \mathrm{Kg}^{0,75}$ e valor médio para digestibilidade de $58,4 \%$.

Ribas et al. (2007) encontraram valores próximos ao deste ensaio, quando avaliaram consumo e digestibilidade aparente, em ovinos, de quatro híbridos de milho (SHS 4040, QPM 129, AG 1051 e BRS 3060), sendo o SHS de ciclo precoce. Os valores médios de CMS e DAMS foram de 64,9 $\mathrm{g} / \mathrm{kg}^{0,75} \mathrm{e}$ $66,9 \%$ DAMS, respectivamente.

Os estudos com genótipos precoces e super-precoces adaptadas às condições semi-áridas, com o propósito de produção de silagem, são escassos. Os dados do presente trabalho, quando comparados aos de silagens obtidas de genótipos recomendados para este propósito, apresentam valores próximos, indicando que o consumo e os coeficientes de digestibilidade da matéria seca, matéria orgânica e proteína bruta não são limitantes para a utilização das silagens dos genótipos estudados.

Estudos que contemplem a avaliação de parâmetros agronômicos, como produtividade, susceptibilidade a pragas e doenças, assim como pesquisas de viabilidade econômica são necessários para que estes genótipos possam ser indicados com segurança para a produção de silagens em condições semiáridas.

\section{Conclusões}

Não foram observadas diferenças entre as silagens dos seis genótipos de milho precoce ou superprecoce. O consumo e os coeficientes de digestibilidade não são fatores limitantes para a utilização das silagens dos genótipos adaptados às condições semi-áridas.

\section{Referências Bibliográficas}

CARVALHO, H.W.L. de; SOUZA, E.M. de. Ciclos de seleção de progênies de meios-irmãos do milho BR 5011 Sertanejo. Pesquisa Agropecuária Brasileira, v.42, n.6, p.803-809, 2007.

FREITAS, G.A.R.; COELHO, S.G.; GONÇALVES, L.C. et al. Consumo e digestibilidade aparente da matéria seca, proteína e energia bruta, e balanço de nitrogênio das silagens de cinco genótipos de milho. Arq. Bras. Med. Vet. Zootec. vol.55, nº.4, 2003.

RIBAS, M.N.; GONÇALVES, L.C.; IBRAHIM, G.H.F.; et al. Consumo e digestibilidade aparente de silagens de milho com diferentes graus de vitreosidade no grão. Revista Brasileira de Milho e Sorgo, v.6, n.1, p.104-115, 2007

SILVA, D.J.; QUEIROZ, A.C. Análise de alimentos: métodos químicos e biológicos. 3.ed. Viçosa, MG: UFV, 2002, 235p.

SILVA, J.F.C.; LEÃO, M.I. Fundamentos de nutrição dos ruminantes. Piracicaba: Livroceres, 1979. 380 p.

VALADARES FILHO, S.C.; PAULINO, P.V.R.; MAGALHÃES, K.A.; et al. Exigências nutricionais de zebuínos e tabelas de composição de alimentos BR-Corte. 1.ed. - Viçosa: UFV, DZO, 2006, 142p. 